\title{
ARE SMALL URBAN CENTERS SUSTAINABLE? A STUDY OF THE NORTH TWENTY- FOUR PARGANAS OF WEST BENGAL
}

\author{
Piyashee Mallik \\ School of Oceanographic Studies, Jadavpur University, Kolkata, India \\ Email: piyasheemallik@gmail.com
}

\begin{abstract}
A substantial proportion of the population of the developing nations either lives in small urban centers or are inhabitants of rural areas relying on small urban centers for access to markets, services, and government facilities. Urban development should be guided by sustainable planning and management vision to ensure mixed-use development. Measuring sustainability in urban areas is a challenging task in itself as it encompasses social, political, economic and environmental components. This study focusses on the sustainability of small urban centers in the North Twenty-Four Parganas district of West Bengal. Hot Spot Analysis and Principal Component Analysis conducted on several chosen parameters resulted in the identification of such urban centers which can act as growth poles as well as small urban centers which if supported by local and national governments have the ability to sustain in the long run.
\end{abstract}

Key words: Small Urban Centers, Urban development, Sustainability, Hotspot Analysis

\section{Introduction}

Sustainable urban development consequent upon the successful management of urban growth is pivotal to the implementation of the United Nations 2030 Agenda for Sustainable Development (UN Nations). This becomes highly significant in developing nations where a gradual and sustained rural to urban migration has been noticed in recent times. The 2018 Revision of World Urbanization Prospects produced by the Population Division of the UN Department of Economic and Social Affairs (UN DESA) reveals that India, China, and Nigeria collectively will account for 35 percent of the projected urban population growth of the world between 2018 and 2050 (United Nations, 2018). In the case of India, the level of urbanization in West Bengal increased from 27.81 percent in 2001 to 31.16 percent in 2011 (Census of India, 2011). One of the striking features of urbanization that the Census 2011 brought into light is the fact that for the first time the absolute growth in urban population ( 91 million) was higher than its rural counterpart thereby influencing the increase in number of Census Towns (CTs) from 1,362 to 3,894 (Bhagat, 2011; Kundu, 2011). Although there is a steady growth of large cities, the population of small urban centers (class II to class V towns based on Government of India's classification) in general has shown a marked increase in the last decade. A good number of these small urban centers have the qualities (as in, diversified economy and infrastructural amenities) to attracting a huge number of populations and sustaining them over the years (Denis et al., 2012). Globally, about 1.5 billion people live in these 'small urban centers' and Africa, Asia, and Latin America constitute almost three-quarters of this population. Reports predict that a large portion of the world's population will be accommodated in these 'small urban centers' at least until 2025 (Satterthwaite, 2006). Constantinos Dioxides, while stressing the significance of small urban centers, argued that the small towns can make themselves reliable and valuable for their inhabitants by providing employment, certain basic amenities and a community life that is often absent in bigger cities (Dioxides, 1965; Abou-Korin, 2014).These small urban centers, through the mechanism of 'spread' and 'trickling down', provide basic necessities in the form of civic amenities, relied upon by the rural areas. Besides, the small 
urban centers promote rural and regional development by contributing directly to production and institutional structures (Rondinelli, 1988; Rondinelli, 1991; Evans, 1992; Gaile, 1992 ;) and play key roles in the successful dissemination of knowledge and technology, widespread transmission of government policies and modernization (Hinderink and Titus, 2002; Satterthwaite and Tacoli, 2003) (Tacoli, 2002; Tacoli, 2003). The global report of UN-Habitat entitled "Meeting Developmental Goals in Small Urban Centers-Water and Sanitation in the World's Cities 2006" reiterates that despite being important linkages between larger cities and the rural hinterland by means of flow of capital, goods, and migration of people, the small urban centers have not been extensively explored till date (Un-Habitat, 2012). Since small urban centers play a crucial role in strengthening local economic development and reduction of poverty (Owusu, 2008) and serve as an interface between agriculture and urban market (Raman et al.,2015), it is imperative to focus on the growth of these small urban centers as well as their ability to sustain in the future. In case of India in general and West Bengal in particular, there has been a rapid growth of small urban centers and the fact whether all of these urban centers will be able to sustain in the coming years or not calls for attention. As a further matter, the provision of basic civic amenities lies behind an urban center's capability to survive in future, and therefore urban local bodies should ensure that the development of civic amenities remains at par with the rapid increase of population. In a previous study (Mallik, 2018), we assessed the sustainability of class I towns in the district of North Twenty-Four Parganas. In this study, we extend that approach by focusing on the small urban centers in the district of North Twenty-Four Parganas to explore the recent phenomenon of the gradual upsurge of small urban centers and assess their sustainability in near future.

The district of North Twenty-Four Parganas $\left(22^{\circ} 8^{\prime \prime} \mathrm{N}\right.$ latitude to $23^{\circ} 16^{\prime \prime} \mathrm{N}$ latitude and $88^{\circ} 18^{\prime \prime}$ E Longitude to $89^{\circ} 4^{\prime \prime}$ E longitude) (Figure 1) consists of five sub-divisions, namely, Bongaon, Barasat, Barrackpore, Bidhannagar, and Basirhat. There are 22 Community Development (C.D.) Blocks, 29 Urban Local Bodies (Statutory Towns) and 78 Census Towns in the district. As per the 2011 Census, North Twenty-Four Parganas is the second-highest populated district in the country and the highest populated district in the state with a population of $1,00,09,781$. With a population density of 2,445 persons per sq. $\mathrm{km}$., it secures the third position among other districts of West Bengal. Besides, with an urban population density of 9,160 persons per sq. km., it ranks second, just after the state capital Kolkata (Census of India, 2011).

The main objectives of this study include the following:

i) to examine the pattern of distribution of the urban centers,

ii) to identify the urban centers based on their population size and civic amenities,

iii) To find out the existing gaps in civic amenities.

iv) to classify the urban centers according to their economic and administrative status,

v) To assess the sustainability pattern of the urban centers.

The pre-field work included going through a wide range of books and published research articles to have an extensive idea about the growth of urban centers and the parameters related to their ability to sustain. A pilot survey of the area has been done in the field and visits were made to the important urban centers and relevant maps and secondary data were collected from Govt. and non-government offices. The secondary data for this work has been collected from different sources namely, the Census of India (2011) and the Bureau of Applied Economics and Statistics, Govt. of West Bengal. The collected data have been processed using statistical techniques, namely Hot Spot Analysis (through ArcGIS 10.3) and Principal Component Analysis (through EXCELSTAT 2014), followed by observation and interpretation of the analyzed data. 


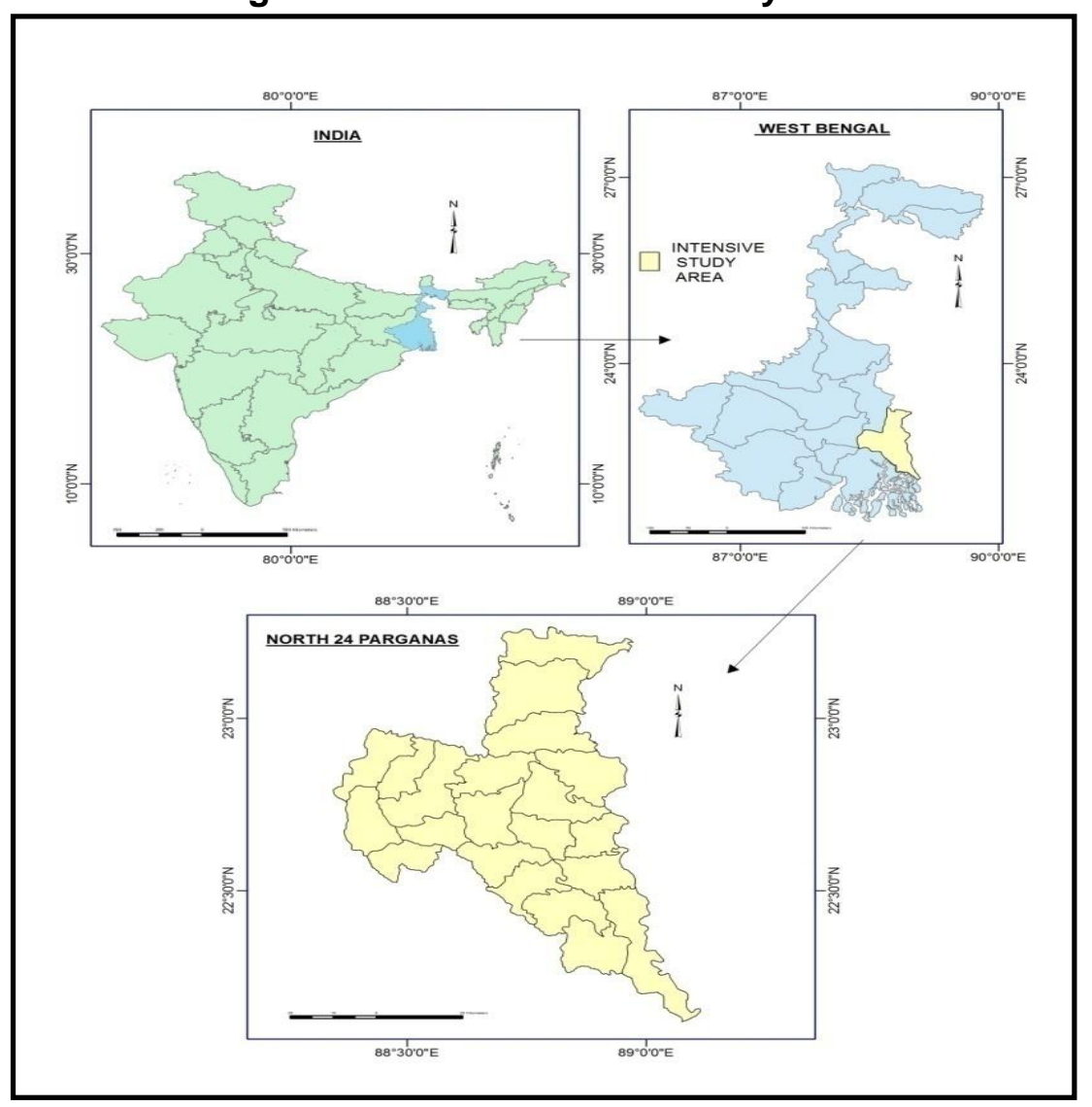

A total of 85 towns of North Twenty-Four Parganas have been considered for this study. These towns are further classified based on their population size, as in towns with 100,000, and the above population sizes are classified as Class-I towns, towns with 50,000 to 99,999 population are classified as Class -II towns, towns having 20,000 to 49,999 population are Class - III towns, those having population between 10,000 to 19,999 are demarcated as Class - IV towns and towns having population between 5,000 and 9,999 are designated as Class -V towns. Towns having a population lower than 5,000 (Class VI towns) have been excluded from this study. The definition of small towns, according to Government of India's official definition, is the agglomerations with such a range of population that fall under the categories of class II to class $V$ towns (Pedersen, 2003). The six variables, on which the analyses are based, include the population of each town, length of road (in km), number of schools, sources of water supply, number of centers of medical facilities (Hospitals, Health Centers and Nursing Homes) and number of cinema halls. In case of absence of numerical data for sources of water supply, discreet numerical scores have been assigned: two (2) for Bore Well Pumping Station (BWP), four (4) for Service Reservoir (SR), 6 for Pressure Tank (PT), and eight (8) for Bore Well Tank (BWT) and ten (10) for Over Head Tank (OHT). In case a service is not available in the town, the name of the nearest place and its distance from the corresponding town, where the facility is available, has been taken into account. For simplification of calculations, a fixed score of 0.5 has been assigned for such cases irrespective of the distance to the nearest facility.

\section{Analysis}

ArcGIS 10.3.1 software has been used for conducting Hot Spot Analysis. Hot Spot Analysis requires calculating the Getis-Ord $\mathrm{Gi}^{*}$ statistic (pronounced $\mathrm{G}$-i-star) for each feature in a dataset (GIS Analysis (2016). The resultant Z-scores and p-values highlight where features with either high or low values cluster spatially. This tool looks at each feature within the context of its nearest features. A feature with a high value is interesting but may not be a statistically significant hot spot. To be a statistically significant hot spot, a feature ought to have a high value 
and be surrounded by other features with high values as well. The local sum for a feature and its neighbors is then compared proportionally to the sum of all features; a statistically significant Z-score result when the local sum is very different from the expected local sum, and when that difference is too large to be the result of random chance. The $\mathrm{Gi}^{*}$ statistic returned for each feature in the dataset is the Z-score. For statistically significant positive Z-scores the larger the $Z$-score, the more intense will be the clustering of high values (hot spot). For statistically significant negative Z-scores, a smaller Z-score corresponds to more intense clustering of low values (cold spot). The Getis-Ord local statistics is given by:

$$
G_{i}^{*}=\frac{\sum_{j=1}^{n} w_{i, j} x_{j}-\bar{X} \sum_{j=1}^{n} w_{i, j}}{S \sqrt{\frac{\left[n \sum_{j=1}^{n} w_{i, j}^{2}-\left(\sum_{j=1}^{n} w_{i, j}\right)^{2}\right]}{n-1}}}
$$

Where $x_{j}$ denotes the attribute value for $j^{\text {th }}$ feature, $w_{i, j}$ is the spatial weight between feature $i$ and $j, n$ is equal to the total number of features and

and

$$
\bar{X}=\frac{\sum_{j=1}^{n} x_{j}}{n}
$$

$$
S=\sqrt{\frac{\sum_{j=1}^{n} x_{j}^{2}}{n}-(\bar{X})^{2}}
$$

This $G_{i}^{*}$ statistic is the Z-score that is computed.

Hot Spot Analysis has been conducted based on GiZScores, taking the following two criteria into account:

i) Combining all the amenities present in each town

ii) Combining population and all the civic amenities of each town.

Figure 02: Hotspot analysis for Class II (top two figures) and Class III (bottom two figures) towns.

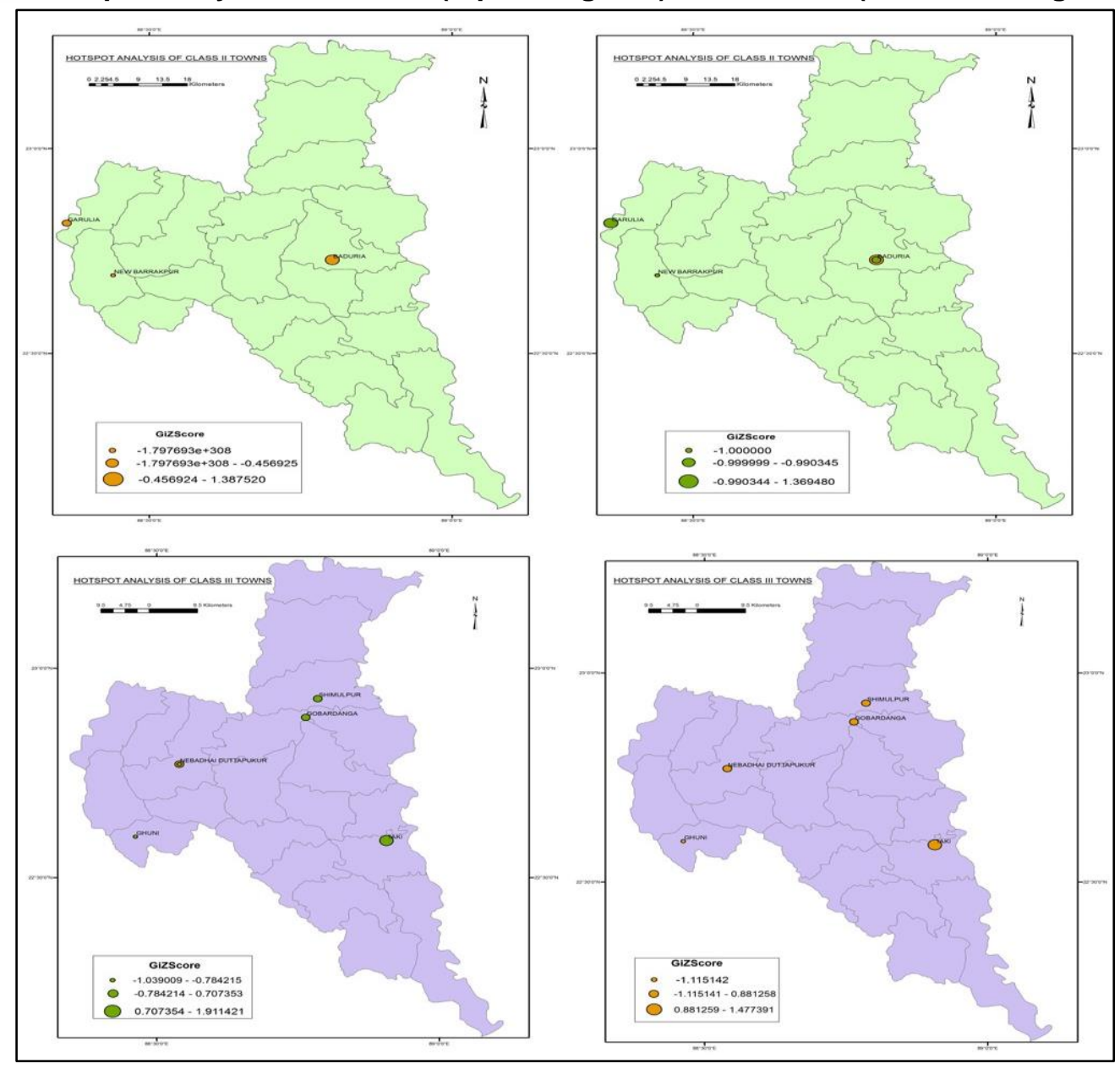


The subfigures on the left side represent hotspot analysis based on the sum of amenities (displayed through orange circles). In the sub-figures on the right side, hotspot analysis based on the sum of population and amenities (displayed through green circles) is superimposed on the hotspot analysis based on the sum of amenities only.

The two-way Hot Spot Analysis indicates that Taki, Noapara, Patulia, Ruiya, Chak Kanthalia, Chandpur, Jafarpur, Kaugachhi, Teghari, Itinda and Mohanpur have sufficient civic amenities as well as a higher concentration of population. Therefore, these towns can be said to have reached an optimum level of urbanization and can act as growth poles i.e. urban centers with certain attributes that facilitate the flow of goods and services among individual households, firms, and governmental entities. These facilities, if augmented by a measure of investment support, will trigger regional and economic development in their hinterlands. They can act as service centers and hubs for surrounding not-so -developed urban centers, exploiting their potential as attractive places to live and work and thus might achieve sustainability. Baduria, Nebadhai Duttapukur, Talbandha, Muragachhi, Deara, Digha, Bilkanda, Purba Narayanpur, and Bandipur are seen to have achieved somewhat sufficiency in civic amenities but their population strength is not so high i.e. the amenities present in these towns are comparatively more than what their current population requires. This means these towns are somewhat going through the process of urbanization and have the ability to accommodate more people based on their more than a sufficient number of civic amenities (Figures 2 - 4). This situation would warrant a focus on the towns' economic development so as to ensure the generation of income and employment. The Hotspot Analysis has also helped to identify another category of towns. The civic amenities present in towns like Garulia, Sadpur, Betpuli, Gangapur, Chikanpara, Dogachhia, Bara Bamonia, Anarberia, Dhanyakuria, etc. are not proportional to the total population of these towns. This indicates that, just like the Third World cities, these towns have grown physically and demographically without proper development of

Figure 03: Hotspot Analysis for Class IV Towns

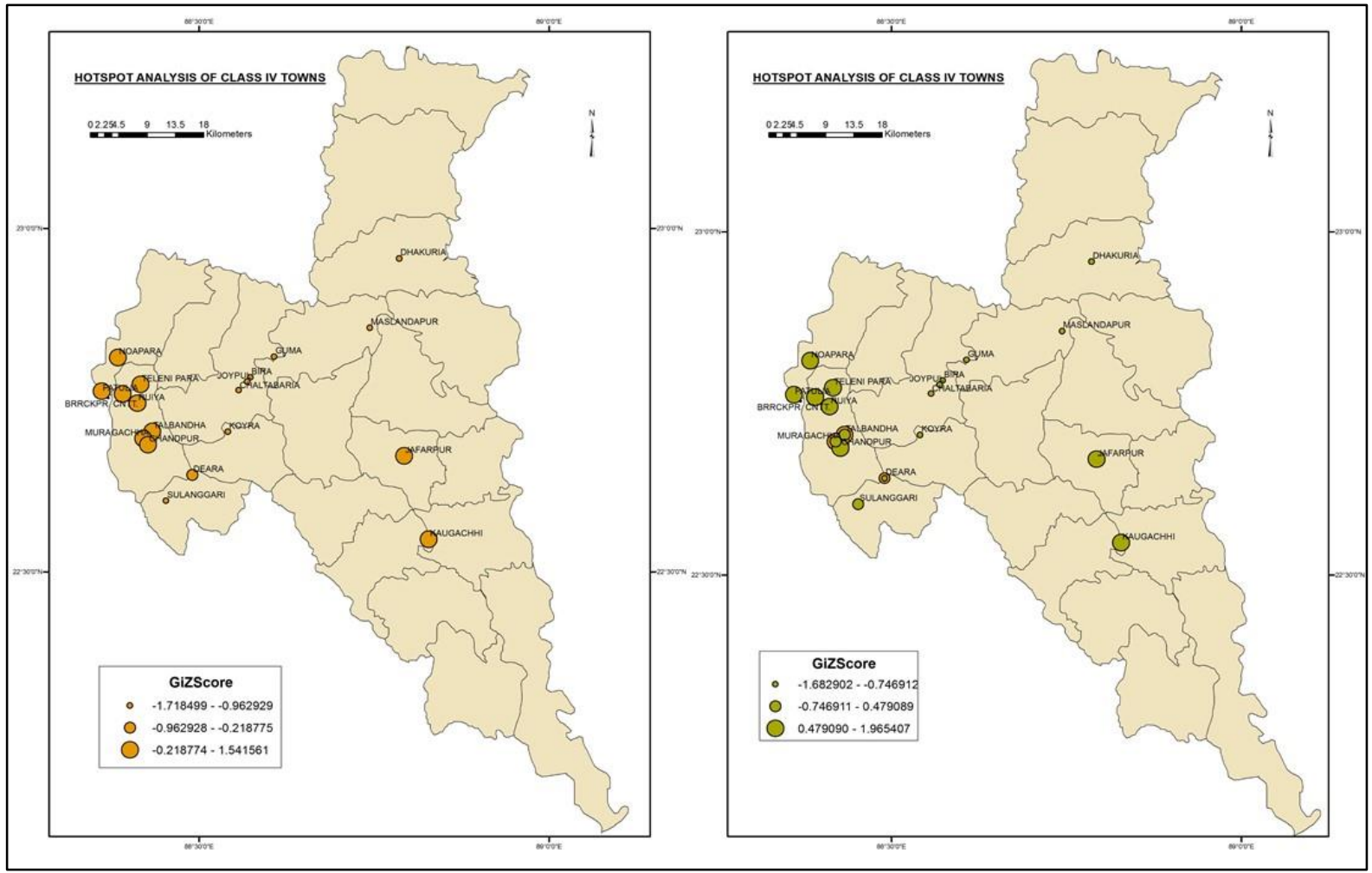

The subfigure on the left side represents hotspot analysis based on the sum of amenities (displayed through orange circles). In the subfigure on the right side, hotspot analysis based on the sum of population and amenities (displayed through green circles) is superimposed on the hotspot analysis based on the sum of amenities only. 
genuine resources to build essential infrastructure and indispensable services for their populations. This suggests that in the long run these towns may either get merged to other large towns or cease to exist until and unless sufficient civic amenities (namely, availability of public facilities, efficacious urban governance, all-inclusive growth management policies for sustainable urban growth, etc.), which can sustain the burgeoning inner and peri-urban populations, are incorporated in these towns. An important thing to note here is that the ability of these small urban centers to sustain in the long run does not merely depend on the provision of basic civic amenities and services. This is because there lies a phenomenally rich and diverse set of circumstances that are unique to each urban center. An urban center will only sustain in the future if it gets the much-needed support from local and national governments for local development and resource mobilization which is further dependent upon the urban centers' potential and constraints.

Figure 04: Hotspot analysis for Class V Towns

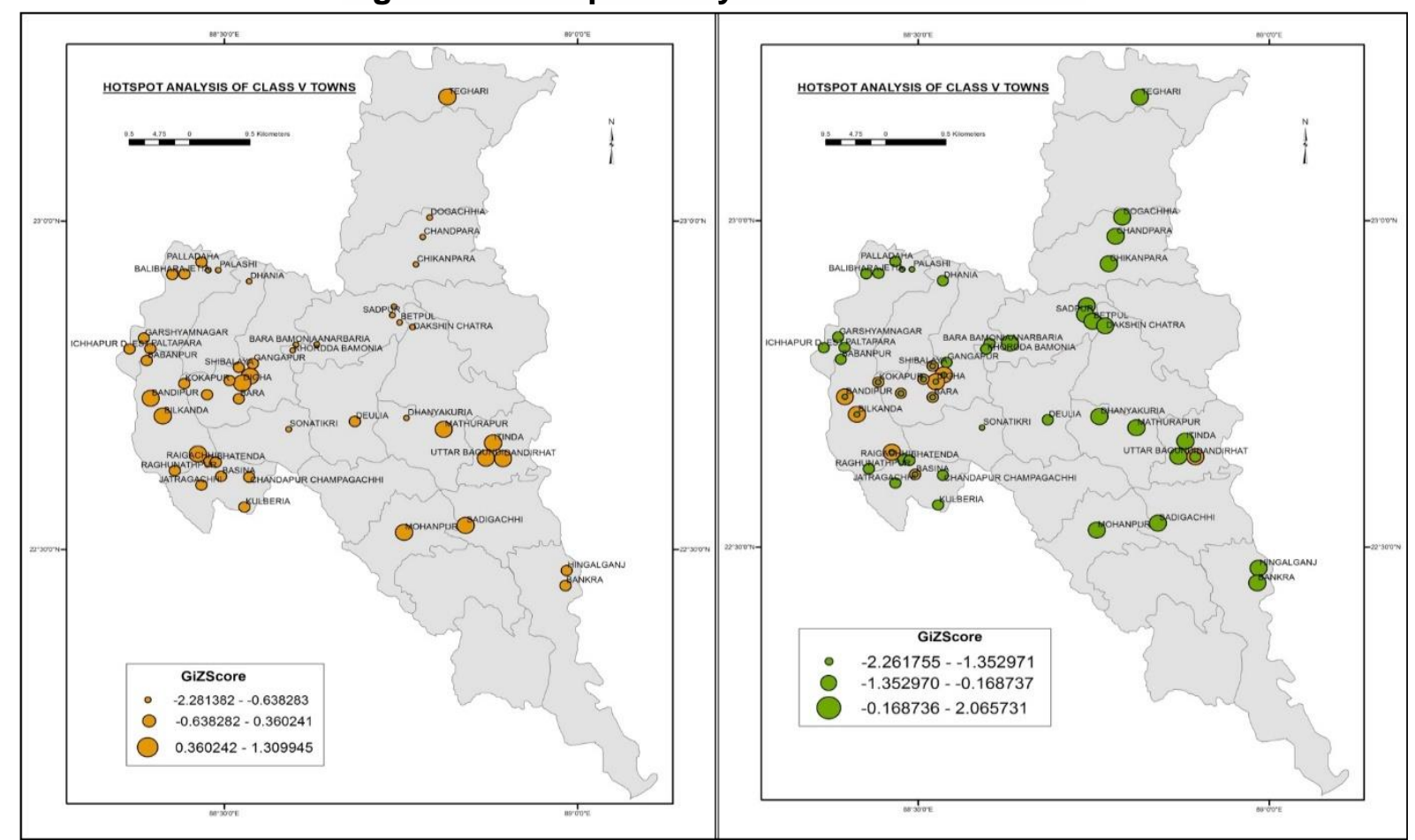

The subfigure on the left side represents hotspot analysis based on the sum of amenities (displayed through orange circles). In the subfigure on the right side, hotspot analysis based on the sum of population and amenities (displayed through green circles) is superimposed on the hotspot analysis based on the sum of amenities only.

Principal Component Analysis has been performed to identify the towns that have undergone optimum urbanization and towns, which are going through urbanization. PCA has been performed for each class of towns separately and each such analysis reveals different dominant variables for each class of towns. Factor loadings for Class II Towns reveal road length, sources of water supply, the number of schools and number of cinema halls has positive correlations and they are highly correlated. Here, the first factor explains 70.25 percent variability. Four variables namely road length, sources of water supply, number of schools and number of cinema halls have major contributions. However, the number of medical facilities becomes dominant in secondary factor loading. Among class II towns, only Baduria shows up as a town going through urbanization (Figure 5). 
Figure 05: Observation chart (observations in the PCA space) for Class II Towns

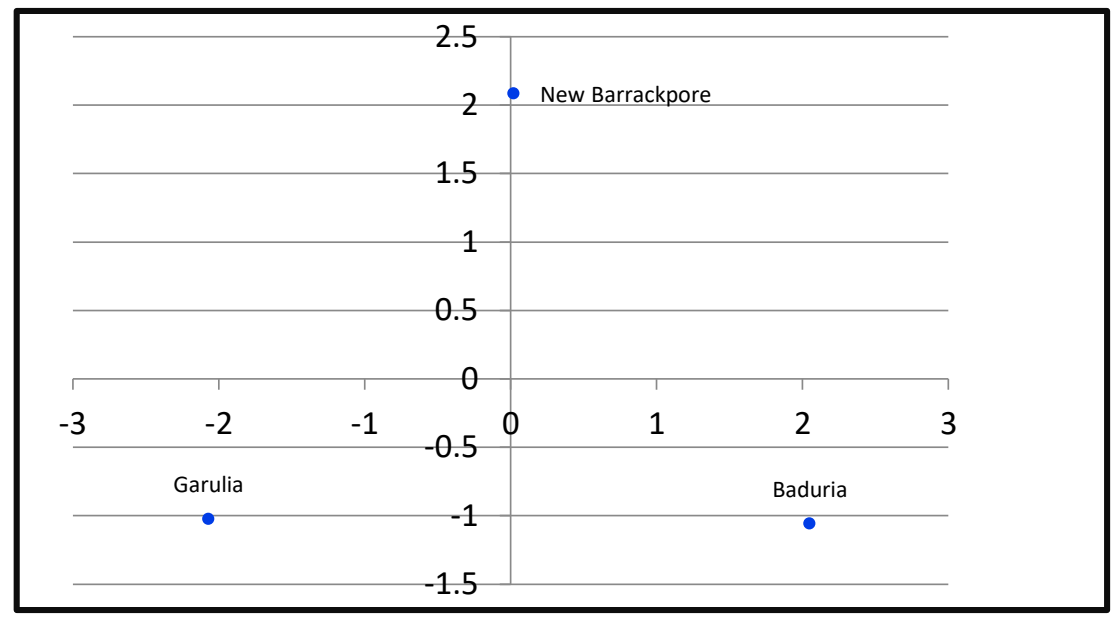

Each town is plotted according to their factor scores, which represent their observation coordinates on the PCA dimensions.

Based on the first factor loadings of Class III Towns, it can be said that road length and number of medical facilities are dominant variables. In secondary loading, however, water shows dominance but road length and number of medical facilities also contribute positively. If we move on to the third factor loadings, number of cinema halls emerges as the most dominant variable. Gobardanga shows high positive loading in both primary and secondary stages, which indicates its optimality of urbanization (Figure 6).

Figure 06: Observation chart (observations in the PCA space) for Class III Towns

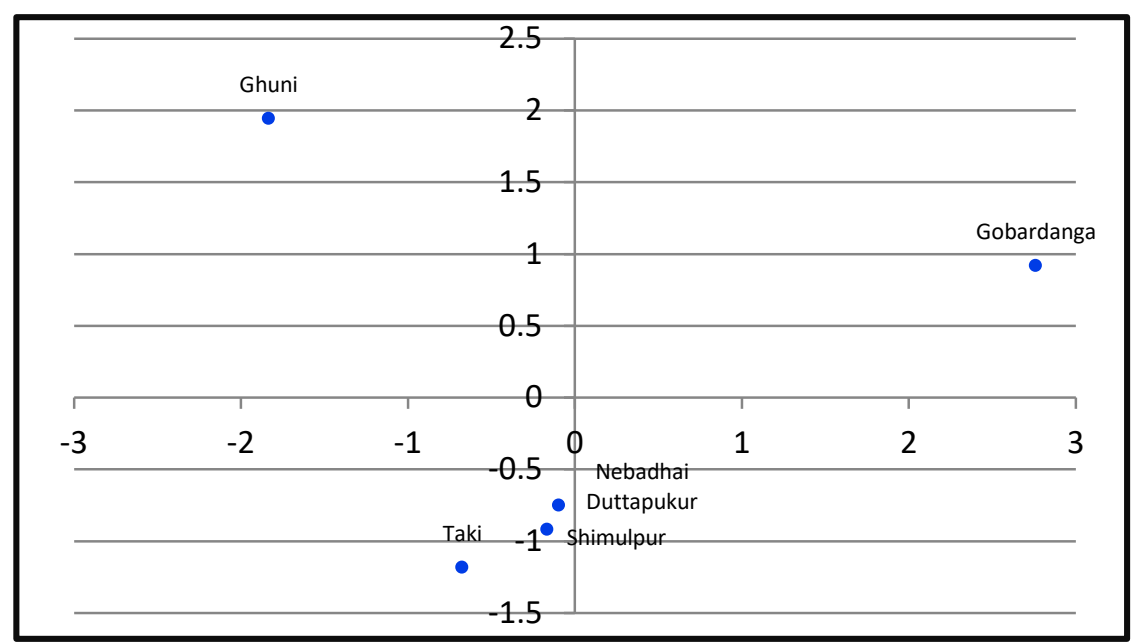

Each town is plotted according to their factor scores, which represent their observation coordinates on the PCA dimensions.

Principal Component Analysis of Class IV towns shows that sources of water supply and the number of medical facilities show high dominance in primary loading; in secondary stage the number of cinema halls is the most dominant variable. Contrastingly, the number of schools shows a strikingly high loading in the third factor loading. In the fourth factor loading, all the variables except sources of water supply show positive influence. So, it can be said that the people residing at Maslandapur, Chandpur, Guma, Dhakuria, and Sulanggari have access to adequate amenities as evident from the biplot. Noapara, Barrackpore Cantonment, Deara and Kaugachhi have sufficient sources of water supply and medical facilities but they lack in cinema halls (Figure 7). 
Figure 07: Observation chart (observations in the PCA space) for Class IV Towns

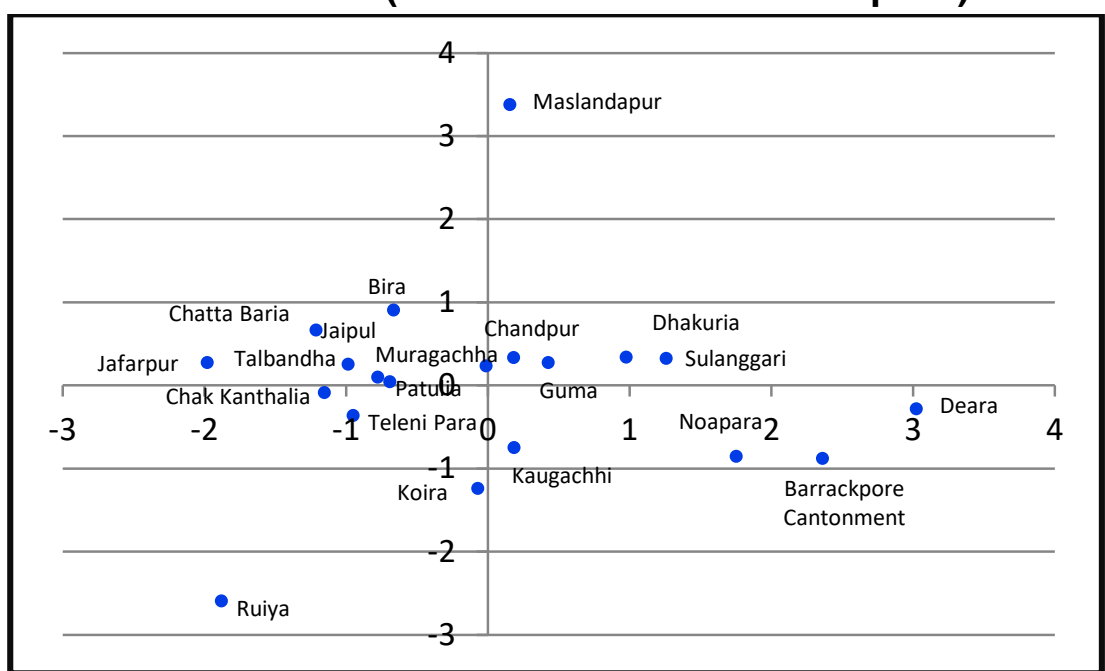

Each town is plotted according to their factor scores, which represent their observation coordinates on the PCA dimensions.

In case of Class $V$ towns, sources of water supply and the number of schools show high dominance in primary loading; at the same time, the number of medical facilities and the number of cinema halls also show positive loading. However, in the secondary stage water and school show negative loading, but cinema and medical show high positive relationship. Number of medical facilities is also dominant in the third factor loading. In the fourth factor loading road length and sources of water supply are dominant variables. Therefore, in this case, the number of medical facilities and cinema halls emerge as influential variables. Based on this, towns like Dhania, Bilkanda, Chandrapur, Sonatikiri, Bhatenda, Dhanyakuria, Basina, Uttar Bagundi, Dandirhat, Jetia, Dakshin Chatra, and Bara emerge as having enough amenities to sustain their current population quite sufficiently (Figure 8).

Figure 08: Observation chart (observations in the PCA space) for Class V Towns

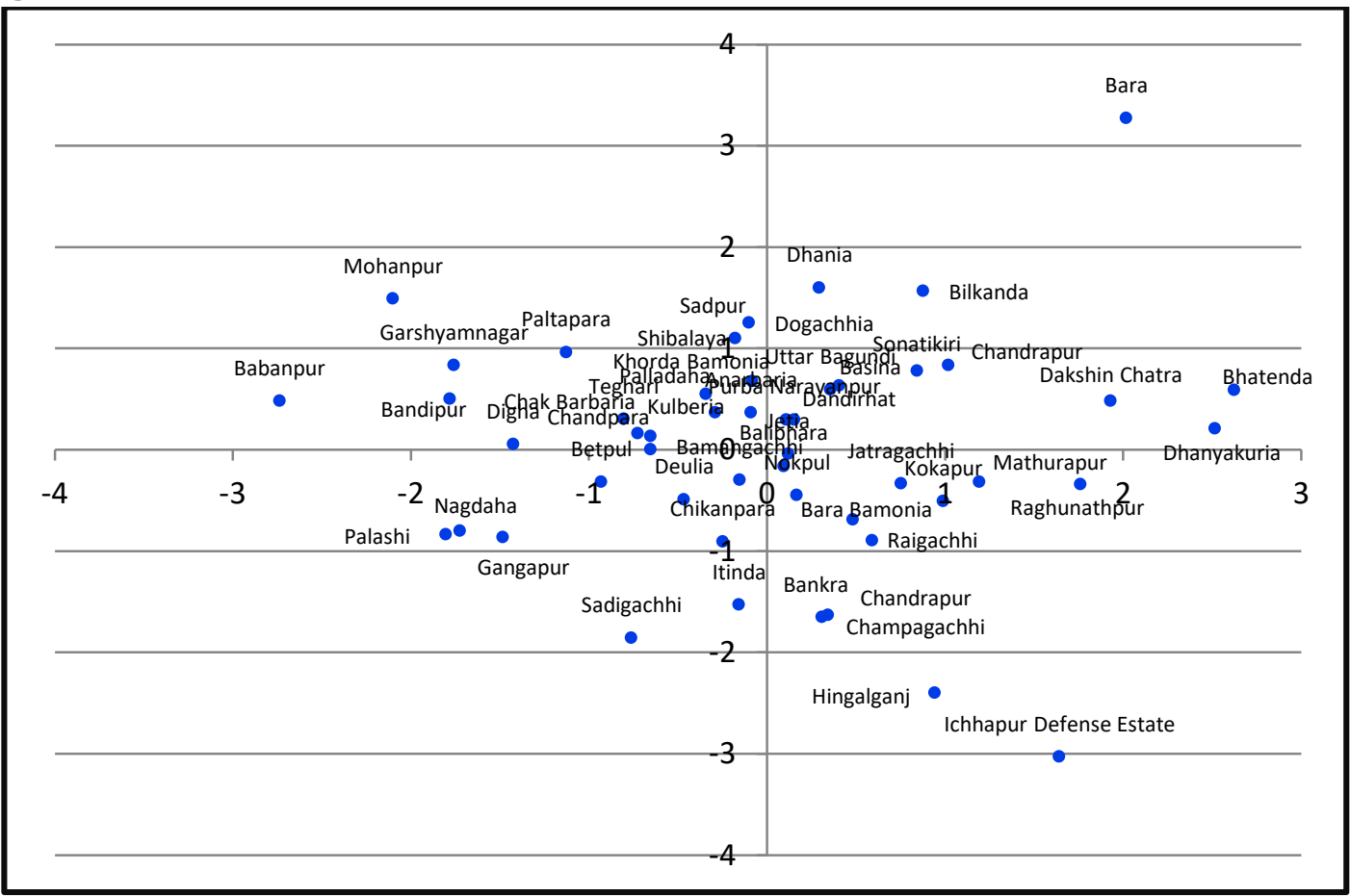

Each town is plotted according to their factor scores, which represent their observation coordinates on the PCA dimensions. 


\section{Conclusion}

If the results of Hotspot Analysis and Principal Component Analysis are focused on together, 7 towns, namely, Gobardanga, Chandpur, Noapara, Barrackpore Cantonment, Kaugachhi, Uttar Bagundi, and Mathurapur come up as towns that have reached the optimum level of urbanization. These towns act as growth poles that would serve nearby urban centers by concentrating populations for productive ventures, achieving economies of scale in areas of energy, housing, transportation, and supporting land use connectivity (Gantsho 2008). Even after reaching the optimum level of urbanization, they will continue to attract people from small urban centers and henceforth are capable of sustaining in the long run. Baduria, Muragachha, Deara, Bilkanda, Chandrapur, Dandirhat, Basina, Bara, Raigachhi and Kokapur, in terms of their locational advantages of being resource-based, tend to accommodate more population in the future. Good local governance, modern planning policies, fostering entrepreneurship, proper management of these urban centers through information sharing and adoption of principles that cater to strengthening linkages between these centers and surrounding areas would help these towns grow into large urban centers in the coming years. Rest of the towns has not been taken into consideration because of either of the following reasons (which, if not supported by quality infrastructure, would potentially fail to sustain in the future):

i) Meager civic amenities (as revealed by hotspot analysis) incapable of fulfilling the needs of the people. Towns that fall into this category most likely will either get merged into other large towns or cease to exist.

ii) Negative loadings on either the first or second factors or on both the factors.

It can be said that these towns have qualified the urban status because of their population size without necessary infrastructures. Kingsley Davies defined urbanization as a process of the switchover of human settlements from rural areas to urban centers (Kingsley, 1962). In the long process of urbanization, there develops an almost completely urbanized society, with the majority of the people living in just a few large places. In the present instance, a rapid process of urbanization has been taking place as the small urban centers boast of better social and economic conditions consequent upon the significant increase in service sectors. This analysis also recognized some urban centers, which, if not supported by quality infrastructure, would potentially fail to sustain in the future. Nonetheless, there remain certain unexplored areas that prove to be of ample scope for future academic research in this field.

\section{Acknowledgement}

The author thanks Dr. Uttam Mukhopadhyay for his ideas and valuable suggestions in enriching the article and Dr. Dipanwita Chattopadhyay for her relevant and helpful inputs related to ArcGIS analyses.

\section{References}

1. Abou-Korin, A. A. (2014). Small-size urban settlements: Proposed approach for managing urban future in developing countries of increasing technological capabilities, the case of Egypt. Ain Shams Engineering Journal, 5(2), 377-390.

2. Bhagat, R. B. (2011). Emerging Pattern of Urbanisation in India, Economic \& Political Weekly, 46(34), 10-12.

3. Census of India (2011). District Census Handbook, North Twenty-Four Parganas, West Bengal, (1), 10-12.)

4. Denis, E., Mukhopadhyay, P., \& Zérah, M. H. (2012). Subaltern urbanisation in India. Economic and political weekly, 47(30), 52-62.

5. Doxiadis, C. (1965). The role of small cities. A lecture delivered at the sixty-fifth annual commencement ceremony of Northern Michigan University; 6 June 1965.

6. Evans, H. E. (1992). A virtuous circle model of rural-urban development: Evidence from a Kenyan small town and its Hinterland. The Journal of Development Studies, 28(4), 640-667. 
7. Gaile, G. L. (1992). Improving rural-urban linkages through small town market-based development. Third World Planning Review, 14(2), 131-148.

8. GIS Analysis (2016): Introduction to Hotspot Analysis. CEHI.

9. Hinderink, J., \& Titus, M. (2002). Small towns and regional development: Major findings and policy implications from comparative research. Urban studies, 39(3), 379-391.

10. Kingsley, D. (1962). Urbanisation in India-Past and Future. India's Urban Future, University of California Press, Berkley.

11. Kundu, A. (2011). Method in Madness: Urban Data from 2011 Census, Economic \& Political Weekly, 46 (40), 13-16.

12. Mallik, P. (2018). Development and sustainability of small urban centers: A study on North Twenty-four Parganas of West Bengal. Research Directions, 2(11), May 2018d. ISSN 2321-5488.

13. Owusu, G. (2008). The role of small towns in regional development and poverty reduction in Ghana. International Journal of Urban and Regional Research, 32(2), 453-472.

14. Pedersen, P. O. (2003). The implications of national-level policies on the development of small and intermediate urban centers in Eastern and Southern Africa. Institute for International Studies.

15. Raman, B., Prasad-Aleyamma, M., \& Bercegol, R. (2015). Selected readings on small town dynamics in India.

16. Rondinelli, D. A. (1988). Market towns and agriculture in Africa: The role of small urban centers in economic development. African Urban Quarterly, 3(1-2), 3-10.

17. Rondinelli, D. A. (1991). Asian urban development policies in the 1990s: from growth control to urban diffusion. World Development, 19(7), 791-803.

18. Satterthwaite, D., \& Tacoli, C. (2003). The urban part of rural development: the role of small and intermediate urban centers in rural and regional development and poverty reduction (No. 9). lied.

19. Satterthwaite, D. (2006). Outside the large cities; The demographic importance of small urban centers and large villages in Africa, Asia and Latin America, developed from a background paper for the United Nations Human Settlements Programme (2006), Meeting Development Goals in Small Urban Centers: Water and Sanitation in the World's Cities 2006.

20. Tacoli, C. (2002). Changing rural-urban interactions in sub-Saharan Africa and their impact on livelihoods: a summary (Vol. 4). IIED.

21. Tacoli, C. (2003). The links between urban and rural development. Environment \& Urbanization 15(1):3-12.

22. United Nations. (2018). Department of Economic and Social Affairs. 2018 revision of world urbanization prospects.

23. Un-Habitat. (2012). Meeting Development Goals in Small Urban Centers: Water and Sanitation in the Worlds Cities 2006. Routledge.

24. Gantsho, M. S. (2008). Cities as growth poles: implications for rural development. In Annual Meetings Maputo, Mozambique: African Development Bank. 